\title{
BATHYMETRIC DIFFERENCE IN THE FREQUENCY DISTRIBUTION OF DAILY HAULS BY THE DANISH SEINERS BELONGING TO A FISH-MEAL FLEET IN THE BERING SEA*
}

\author{
Shiro Mrnami and Hiroshi MaÉda \\ (Received April 7, 1965)
}

It was found that the frequency distributions of daily catch by the Danish seiners in the Bering Sea followed either logarithmic normal series or normal one ${ }^{1)}$. But full understanding of catch pattern from the administrative standpoint is possible only when the variation of catch pattern has been clarified in relation to the labor needed or obliged to expend for harvesting the catch. Fishing grounds differ in their evaluation owing to the difference in the following facts: whether fishermen can fortunately get a good catch by only few hauls or they work as hard as possible but yield a poor catch; furthermore, even if all the boats may attain their daily target or yield an equal good catch, whether they get it far within their capacity of daily work or they do so with persevering labor near the hardest extremity.

Daily hauls may be the results of the integrated effects of a lot of factors, such as oceanographic and meteorological conditions, relative abundance and availability of fish population, and even included many psychological factors of fishermen and rate of hours capable of directly engaging in fishing work. In this report, however, the discussion is limited to the relation between the number of hauls in a day and the depth of the fishing ground, because the number of daily hauls differed in accordance with depth and with the grade of catch while the latter changed depending on depth too, and also because magnitudes of some of the factors were difficult to estimate quantitatively and others fluctuated incidentally or were hard to be kept stable.

\section{Method and Results}

The same records as in the case of the discussion on the daily catch (the records during an entire season in 1963 by each of 22 Danish seiners belonging to one of the fish-meal fleets working in the Bering Sea) were employed here, too. All the records were treated being separated into three groups according to locality and season, after removal of the records on the days when some or all of the boats engaged in fishing not throughout the day (chiefly owing to long shift or stormy weather) and those by the boats which could not engage in ordinary work (chiefly owing to being employed in exploratory fishing or rarely accident):

* Shimonoseki College of Fisheries（南 四郎·前田弘：水産大学校）

Contribution from the Shimonoseki College of Fisheries, No. 450 
Area A $\cdots$ North of $58^{\circ} 00^{\prime} \mathrm{N}$ and east of $167^{\circ} 00^{\prime} \mathrm{W}$ (April 19 to June 3)

Area $\mathrm{B} \cdot .58^{\circ} 00^{\prime} \mathrm{N}$ to $60^{\circ} 30^{\prime} \mathrm{N}$ and $171^{\circ} 30^{\prime} \mathrm{W}$ to $175^{\circ} 00^{\prime} \mathrm{W}$ (June 4 to August 3)

Area $\mathrm{C} \cdot 59^{\circ} 00^{\prime} \mathrm{N}$ to $62^{\circ} 30^{\prime} \mathrm{N}$ and $176^{\circ} 30^{\prime} \mathrm{W}$ to $179^{\circ} 00^{\prime} \mathrm{W}$ (August 4 to September 25)

Frequency distribution of daily hauls in respective areas showed a strong bias of the mode towards large number of daily hauls. This suggests that the hardest extremity of daily capacity of work was eleven hauls and unfavorability in many of the factors as a whole cutted down the daily hauls following logarithmic normal series: In short, the frequencies of day-and-boat plotted against $(11-x)$ on logarithmic scale seemed to be agreeable to normal series (here, a boat conducted $x$ hauls a day). But the observed series did not fit to this series. Among many

Table 1. Decrease in daily hauls with increase in depth of fishing ground.

\begin{tabular}{c|c|c|c|c|c}
\hline \multirow{2}{*}{} & & \multicolumn{4}{|c}{ Classes of daily hauls } \\
\cline { 2 - 6 } & & $\leqq 6$ & 7 & $\equiv 8$ & Total \\
\hline \multirow{3}{*}{$\begin{array}{c}\text { Depth } \\
\text { classes }\end{array}$} & $\leqq 104 \mathrm{~m}$ & 98 & 124 & 534 & 756 \\
& $105-124 \mathrm{~m}$ & 289 & 215 & 507 & 1011 \\
& $\equiv 125 \mathrm{~m}$ & 238 & 318 & 291 & 847 \\
\hline & Total & 625 & 657 & 1332 & 2614 \\
\hline
\end{tabular}

$x^{2}=237.59$ for 4 degrees of freedom. Figure in each column shows the frequency of day-and-boat.

Table 2. Fitness of the observed series of frequencies of daily hauls to the theoretical series.

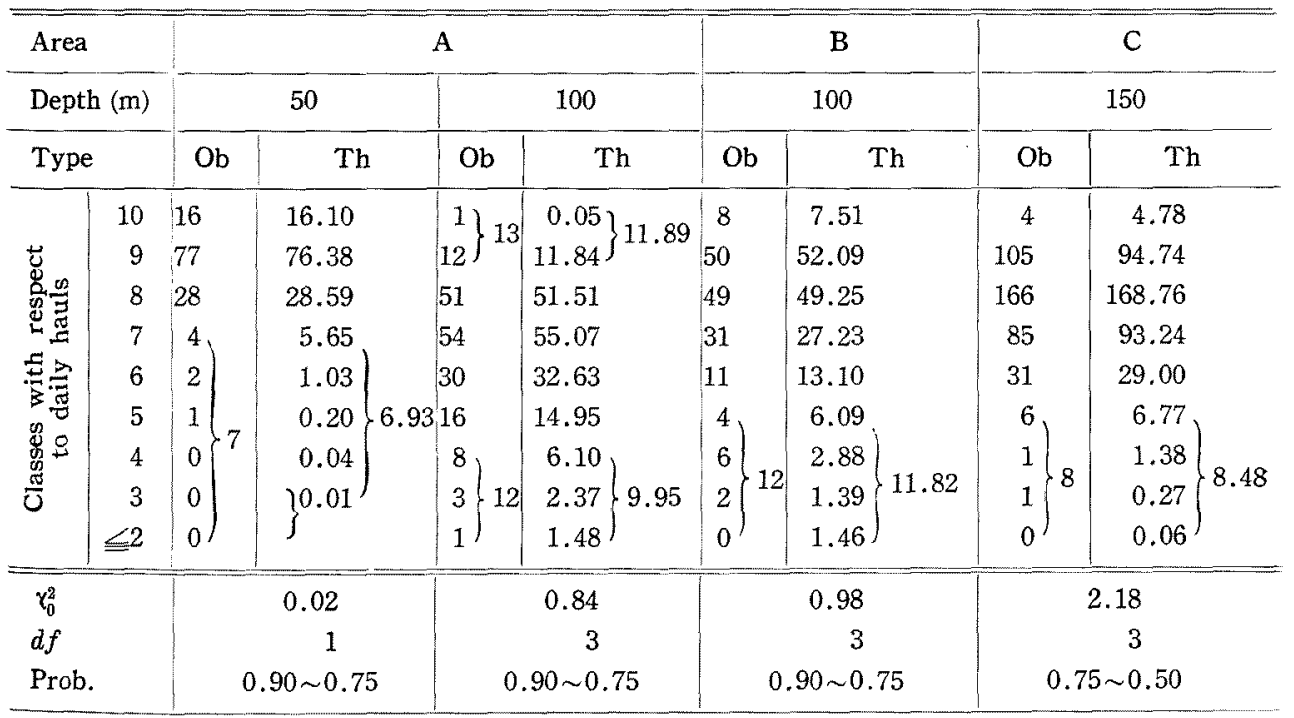

All the values are plotted against $(11-x)$ on logarithmic scale. Filled triangle represent the value observed in Area A; open one that in Area B, while the triangle with rignt half filled that in a Area $C$.

Note: In the theoretical series, the frequency curve plotted against $(11-x)$ on logarithmic scale is set to follow normal distribution (here, $x$ is the daily hauls a boat). 
probably influential factors, the increase in depth may be one of the most effective barriers limiting the daily hauls. And, as shown in Table 1, the preliminary test through chi square revealed that the distribution of daily hauls differed very significantly between depth classes. Therefore, the records of daily hauls were stratified into 11 depth zones of $10 \mathrm{~m}$ interval. In each of the zones, the expectant series of frequency was estimated from the linear relation of STUdent's $Z$ on $\log (11-x)$; then the test of fitness to the theoretical series through chi square indicated that the series of frequency of day. and-boat by depth zones in respect of the daily hauls plotted against $(11-x)$ on logarithmic scale agreed excellently with normal curve. Some examples of the test of goodness of fit are shown in Table 2. The average and standard deviation of daily hauls in respective depth zones are shown in Fig. 1. This figure shows the following tendencies: (1) in Area A, the average of daily hauls decreases sharply in accordance with the increase in depth from $50 \mathrm{~m}$ to $110 \mathrm{~m}$ and the same tendency is true of the standard deviation; (2) the average and standard deviation of daily hauls in Area $B$ are larger than those of the corresponding depth zones in Area A; (3) but the standard deviations of daily hauls in respective depth zones of Area $\mathrm{C}$ are remarkably small and

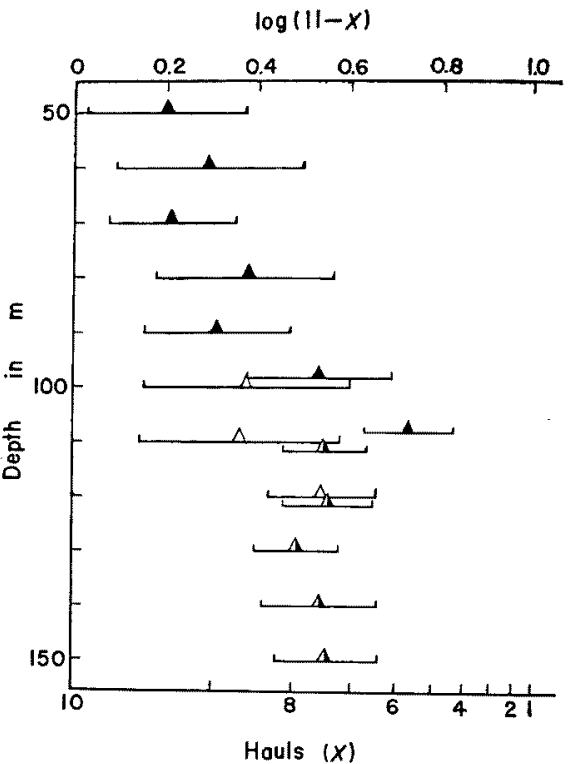

Fig. 1. Bathymetric difference in the average of daily hauls (triangle), with reference to that of standard deviation (true line).

the average values show only slight decrease with increase in depth from $110 \mathrm{~m}$ to $150 \mathrm{~m}$.

\section{Discussion}

Figure 1 shows rough tendency of decrease in daily hauls in accordance with increase in depth, as if suggesting the increase in depth being the barrier of frequent hauling. On the other hand, the average of daily catch in Area A showed, as illustrated in Fig. 1 of the preceding report ${ }^{1)}$, first a slight decrease and then sharp increase in accordance with the increase in depth from $50 \mathrm{~m}$ to $110 \mathrm{~m}$; in Area B, marked increase at $120 \mathrm{~m}$ zone and slight decrease at $130 \mathrm{~m}$ and $140 \mathrm{~m}$ zones; and in Area C, a little marked decrease till $130 \mathrm{~m}$ and increase till $150 \mathrm{~m}$. Thus, the bathymetric difference in daily catch did not show that of relative abundance; and poor catch was harvested by frequent hauls but good catch by not 
frequent hauls, as shown in Table 3.

Further studies are, therefore, needed for telling this tendency of decrease in daily hauls in accordance with the increase in depth is whether the essential one due to the consequence of the increase in depth or due to influence of the increase in catch with that of depth as the obstacle to frequent hauling or nothing but a change one due simply to the result of control of frequency of daily hauls in an attempt to compensate for the bathymetric difference in relative abundance and to supply a stable amount of fish to mother-ship.

Table 3. Inverse relation of daily hauls to daily catch.

\begin{tabular}{|c|c|c|c|c|c|}
\hline & & \multicolumn{4}{|c|}{ Classes of daily hauls } \\
\hline & & $\leqq 6$ & 7 & $\supseteqq 8$ & Total \\
\hline \multirow{2}{*}{$\frac{2}{\frac{\pi}{d}}$} & $\leqq 22$ tons & 119 & 132 & 617 & 868 \\
\hline & $23-32$ tons & 64 & 80 & 334 & 478 \\
\hline \multirow{3}{*}{ 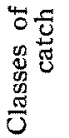 } & $33-39$ tons & 151 & 204 & 182 & 537 \\
\hline & $\geqq 40$ tons & 291 & 241 & 199 & 731 \\
\hline & Total & 625 & 657 & 1332 & 2614 \\
\hline
\end{tabular}

$\chi^{2}=397.57$ for 6 degrees of freedom. Figure in each column shows the frequency of day-and-boat.

\section{Summary}

1. This report deals with the bathymetric difference in the frequency distribution of daily hauls recorded during an entire season in 1963 by 22 Danish seiners belonging to one of the fish-meal fleets working in the Bering Sea.

2. Records were treated being stratified first into three areas according to the difference in locality as well as in season and then into 11 depth zones of $10 \mathrm{~m}$ interval.

3. The series of frequency of day-and-boat by depth zones in respect of the daily hauls plotted against $(11-x)$ on logarithmic scale agreed excellently with normal series (here, a boat conducted $x$ hauls a day).

4. The bathymetric differences in the average and standard deviation of daily hauls are shown in Fig. 1, which shows a rough tendency of decrease in daily hauls in accordance with increase in depth, as if suggesting the increase in depth being the barrier of frequent hauling, although there still remains a doubt whether this tendency is essential or nothing but a chance coincidence.

\section{References}

1) Maf́da, H. and S. Minami: This Bull., 31, 340 (1965).

2) Yamamoto, T.: Statistics and Survey Div., Min. Agric. Forest., Jap. Gov. (1956).

3) YoshinaRA, T.: This Bull., 18, 241-244 (1952). 